\title{
Anotações Históricas e Conceituais sobre o Programa de Pós-Graduação em Psicologia da Universidade Federal do Rio Grande do Sul
}

\author{
Historical and Conceptual Notes about the Graduate Program in Psychology \\ from the Federal University of Rio Grande do Sul
}

\author{
William B. Gomes* \& Claudio Hutz \\ Universidade Federal do Rio Grande do Sul
}

\begin{abstract}
Resumo
Instituições de Ensino Superior foram concebidas no Brasil no século XIX como centros de formação profissional, oferecendo cursos de graduação com pouca atenção à pesquisa. A formação em pesquisa começa a se desenvolver com a fundação da Coordenação de Aperfeiçoamento de Pessoal de Nível Superior do Ministério da Educação (CAPES) em 1951 e, especialmente, após sua reestruturação em 1964. Os programas de pós-graduação em psicologia implantados entre 1965 e 1980 enfrentaram dificuldades de inserção em suas instituições e de assumir um perfil coerente com a formação de pesquisadores e de docentes para o ensino superior. Mesmo assim contribuíram para na formação de doutores e para o desenvolvimento da pesquisa no Brasil. As características atuais foram se delineando na década de 1980 , sendo incorporadas pelos novos programas, dentre eles, o Programa de Psicologia da Universidade Federal do Rio Grande do Sul (UFRGS). Este artigo reúne anotações sobre as condições fundadoras e os fundamentos que estão associadas à trajetória bem sucedida do Programa de Pós-Graduação em Psicologia da UFRGS, descrevendo a história de sua implantação, seus fundamentos, seus princípios básicos e sua forma de funcionamento.

Palavras-chave: História da Psicologia; História da Pós-Graduação; Programa de Pós-Graduação em Psicologia - UFRGS.
\end{abstract}

\begin{abstract}
Brazilian Institutions of Higher Education were conceived in Brazil in the $19^{\text {th }}$ century as centers of professional training which offered undergraduate programs giving little attention to research. A systematic research training started in 1951 with the creation of CAPES, an agency of the Ministry of Education for the Improvement of Higher Education Personnel, and it improved when the agency was restructured in 1964. The Graduate Programs in Psychology implemented between 1965 and 1980 faced insertion difficulties in their institutions and had problems to present a profile which was consistent with the training of researchers and higher education faculty. Nevertheless, they made important contributions to doctorate training and research in Brazil. The current characteristics, designed in the 1980s, were incorporated by the new programs, among them, the Graduate Program in Psychology from the Federal University of Rio Grande Sul (UFRGS). This paper presents some considerations about the founding conditions and the fundamentals that are associated with the successful trajectory of the Graduate Program in Psychology from UFRGS and it describes the history of its foundation, its main principles and the way it is organized.

Keywords: History of Psychology; History of Graduate Studies in Brazil; Graduate Program in Psychology - UFRGS.
\end{abstract}

O Programa de Pós-Graduação (PPG) em Psicologia da Universidade Federal do Rio Grande do Sul (UFRGS) surgiu em 1987 com o Curso de Mestrado, ampliando-se em 1995 para oferecer o Curso de Doutorado. A denomi-

"Endereço para correspondência: Universidade Federal do Rio Grande do Sul, Instituto de Psicologia, Rua Ramiro Barcelos, 2600, Porto Alegre, RS, Brasil, CEP90035-003. Fone: 513308 5115.E-mail: gomesw@ufrgs.br nação oficial do Programa sempre foi "Psicologia". Contudo, por ter definido a "Psicologia do Desenvolvimento" como área de concentração, os Cursos de Mestrado e de Doutorado, e o próprio Programa, vieram a ser identificados e reconhecidos por essa denominação, mesmo em documento oficiais. Só recentemente, em 2007, a denominação "Psicologia" voltou a constar novamente nos documentos da Coordenação de Aperfeiçoamento de Pessoal de Nível Superior (CAPES), como título dos cursos de Mestrado e Doutorado. 
Desde os seus primórdios o PPG em Psicologia da UFRGS despontou como centro de excelência na pesquisa e na formação de docentes universitários, com expressiva inserção internacional, conforme reconhecido nas sucessivas avaliações da CAPES. Atualmente o PPG conta com 18 professores permanentes dos quais 17 recebem bolsas de produtividade do Conselho Nacional de Desenvolvimento Científico e Tecnológico (CNPq), o que o constitui como maior conjunto desses pesquisadores em um único Programa. No Relatório Anual CAPES-2009, a coordenadora Débora Dalbosco Dell'Aglio descreveu o andamento do Programa nos seguintes termos:

O Programa de Pós-Graduação em Psicologia tem se caracterizado por um contínuo crescimento, que pode ser observado pelos resultados da avaliação realizada pela Capes. No triênio 1998/2000 o curso foi avaliado com nota 5, em 2001-2003 fomos avaliados com a nota 6 e, na última avaliação, 2004-2006 obtivemos nota 7. Esta avaliação premiou o esforço dos nossos professores e alunos, reconhecendo a excelência e a internacionalização crescente do nosso Programa, a qualificação do nosso corpo docente, sua significativa produtividade acadêmico-científica e sua capacidade de assumir um papel de liderança e solidariedade acadêmica na área. Para atingir tal nível, nosso Programa passou, e continua passando, por um processo de planejamento estratégico sistemático, com autoavaliações constantes, estimulando a produção qualificada de alunos e professores e o intercâmbio nacional e internacional. Aliado a isso, houve um incremento do investimento em pesquisa pelos órgãos do governo, assim como a possibilidade de contratar novos professores. Nosso Programa aproveitou essas oportunidades, aumentando seu corpo docente e obtendo financiamentos para a pesquisa e intercâmbio.

Pergunta-se, então, o que vem caracterizando a trajetória e o funcionamento deste Programa como condições fomentadoras de sua excelência? Como foi possível reunir em um único grupo tantos pesquisadores vocacionados à pesquisa, dedicado ao Programa e à articulação da ciência psicológica no Brasil? Por que estão sempre dispostos a colaborar com instituições de fomento, sociedades científicas e projetos editoriais?

A presente exposição reúne anotações históricas e conceituais na forma de ensaio compreensivo das possíveis condições que contribuíram para a instalação, desenvolvimento e êxito do Programa de Pós-Graduação em Psicologia da UFRGS. Trata-se, portanto, de um levantamento histórico da fundação e da consolidação do Programa: (a) quanto às pré-condições oriundas das tradições regionais e universitárias de Porto Alegre; (b) quanto às condições que orientaram a preparação e a execução do projeto inicial para o Curso de Mestrado; e (c) quanto aos fundamentos que vêm norteando a vida acadêmica e administrativa. Desse modo será possível rever a trajetória do Programa, da fundação aos fundamentos, tendo como foco os objetivos e práticas que sustentam o traba- lho efetivo dos docentes, discentes e funcionários técnicos administrativos. Oferece ainda um acervo informativo à reflexão e à análise crítica das realizações destes 23 anos de serviço à formação em nível de pós-graduação no Brasil. As anotações apresentadas nesta exposição estão baseadas nos Cadernos Indicadores da CAPES ${ }^{1}$, nos documentos submetidos para credenciamento dos cursos de Mestrado e Doutorado, nos Currículos Lattes dos professores, e em historiografia preparada sobre a Psicologia no Rio Grande do Sul pelo MuseuPsi².

\section{Quanto às Pré-Condições}

Por pré-condições entendem-se aqueles elementos que serviram de base cultural e contextual para a fundação do Programa. Neste sentido, o primeiro reconhecimento vai para a tradição intelectual e científica da UFRGS, cujas primeiras unidades remontam ao final do século XIX e que já ofereciam cursos de mestrado e de doutorado desde os finais da década de 1960. Atente-se que a pós-graduação brasileira estava sendo estruturada exatamente na segunda metade dessa década o que mostra a prontidão acadêmica e científica da UFRGS. Com efeito, o primeiro campus da UFRGS, atualmente Campus Central, reúne um conjunto arquitetônico de prédios históricos, verdadeiros monumentos dedicados ao ensino, à pesquisa e à extensão, estrategicamente localizados entre o belo e aprazível Parque Farroupilha e o centro histórico da cidade de Porto Alegre. A vida universitária foi desse modo uma grande impulsionadora da vida intelectual e artística da capital de um Estado que tem se destacado pelo empenho e determinação na consolidação territorial e política do país.

A tradição da pesquisa em psicologia no Rio Grande do Sul vem de longa data. Remonta às antigas teses da Faculdade de Medicina da UFRGS (terceira mais antiga faculdade de medicina do Brasil, fundada em 1898), (Lhullier \& Massimi, 2006) passando pelo Centro de Estudos e Pesquisas Educacionais da Secretaria de Educação, reconhecido e elogiado por Lourenço Filho (1955/ 1971, 1969/1971), até afirmar-se nos programas de pósgraduação stricto sensu inaugurados no início da década de 1970 (Gomes, DaSilveira \& Gauer, 2006).

A história da pesquisa psicológica no Rio Grande do Sul está associada a três nomes: Irmão Henrique Justo (1922- ), Jurema Alcides Cunha (1925-2003), e Juracy Cunegatto Marques (1931- ). Justo e Marques foram pesquisadores e acadêmicos, comprometidos com a formação de professores-pesquisadores e com a organização de cursos de pós-graduação, tendo inserção direta na criação de programas e na qualificação de professores.

\footnotetext{
1 Ver Cadernos Indicadores da CAPES: http:// conteudoweb.capes.gov.br/conteudoweb/ CadernoAvaliacaoServlet

${ }^{2} \mathrm{O}$ MuseuPsi poderá ser acessado pelo próprio nome através de sistemas de busca da Internet como o Google ou pelo endereço: http://www6.ufrgs.br/museupsi/
} 
Cunha foi pioneira em pesquisa, colaborou com cursos de pós-graduação, destacando-se por se manter fiel a uma linha de investigação e construindo um acervo de dados considerável sobre psicodiagnóstico. Justo e Cunha tornaram-se referências nacionais em assuntos distintos, o primeiro em Psicologia Humanista, e a última em Avaliação Psicológica. Marques exerceu influência na orientação de pesquisa, na diversificação do campo de atuação do psicólogo, e em administração universitária (ver Gomes, 2006). Justo, quando diretor do Instituto de Psicologia da PUCRS, criou oportunidades para professores obterem doutoramento no exterior. Marques desenvolveu o curso de pós-graduação da Faculdade de Educação da UFRGS e foi responsável por trazer para esta universidade importantes nomes da psicologia brasileira, como Angela Biaggio e Aroldo Rodrigues. Após se aposentar na UFRGS, assumiu a coordenação do Programa de PósGraduação em Psicologia da Pontifícia Universidade Católica do Rio Grande do Sul (PUCRS). Jurema A. Cunha trabalhou no programa de Pós-Graduação em Psicologia da PUCRS durante vários anos. Porém, nos últimos anos de sua vida, trabalhou no nosso programa, como professora visitante, com bolsa do CNPq, junto ao Laboratório de Mensuração onde prestou grande colaboração para o desenvolvimento das linhas de pesquisa em avaliação psicológica. Nesse período, ela produziu a última versão do seu livro, Psicodiagnóstico- $V$, editado pela ArtMed, que se tornou o livro texto principal da área de avaliação psicológica, utilizado em praticamente todos os cursos de graduação do país.

No Estado do Rio Grande do Sul, o ensino de Psicologia teve início com as aulas dos professores de Psicologia da Faculdade de Filosofia da UFRGS, na década de 1940. Mas foi em 1953 que a PUCRS propôs, pela primeira vez, um curso de especialização dedicado à psicologia, em nível de pós-graduação lato sensu, colocando-se na mesma posição da Pontifícia Universidade Católica do Rio de Janeiro (PUCRJ), e da Faculdade de Filosofia Sedes Sapientiae em São Paulo, que também estavam criando cursos de especialização por volta de 1953. Depois veio a Universidade de São Paulo criando o Curso Graduação de Psicologia em 1958 (Gomes et al., 2006).

A década de $1960^{3}$ está fortemente associada à implantação dos cursos de graduação em Psicologia. No entanto, é nesta mesma década, no bojo das reformas universitárias, que os cursos de pós-graduação stricto sensu ganham forma no Brasil. Em 1964, a CAPES foi reorganizada, passando a ser denominada de Coordenação de Aperfeiçoamento de Pessoal de Ensino Superior. O primeiro programa de pós-graduação stricto sensu em Psicologia, no Brasil, foi o Mestrado em Psicologia Clínica da PUCRJ, criado em 1966. Em segundo lugar,

\footnotetext{
${ }^{3}$ As informações que seguem foram obtidas em Ferreira e Moreira (2002).
}

vieram os Mestrados em Psicologia Experimental, e em Psicologia Escolar e do Desenvolvimento da Universidade de São Paulo (USP), criados em 1970. A terceira leva de novos programas ocorreu em 1972, com a criação dos mestrados de Psicologia Social na PUCSP (Pontifícia Universidade Católica de São Paulo), de Psicologia Clínica na PUCCAMP (Pontifícia Universidade Católica de Campinas - SP), e de Psicologia Aplicada na PUCRS. O Curso de Mestrado em Psicologia Aplicada foi o primeiro programa de pós-graduação stricto sensu da PUCRS (Vaz, 1987), tendo como objetivo o desenvolvimento das áreas tradicionais de formação: clínica, escolar, e organização. Pode-se acrescentar a esta lista a criação, também em 1972, do Curso de Mestrado em Educação na UFRGS, com uma área de concentração em Psicologia Educacional dirigida a psicólogos e a professores de psicologia com no mínimo dois anos de exercício (Gauer \& Gomes, 2002).

Os primeiros programas de pós-graduação no Brasil não contavam com um modelo para ser aplicado e adaptado as suas características e interesses. Eles refletiam a transição da tradição da defesa de tese como única exigência de titulação para um programa com exigências curriculares e condução de pesquisa colaborativa e continuada. Entre os professores, debatiam-se as vantagens e as desvantagens das tradições da Europa, com ênfase na preparação da tese, e dos Estados Unidos da América (EUA), com ênfase em programa constituído por disciplinas correlacionadas e pela preparação do trabalho de conclusão (tese ou dissertação). Obviamente, cada professor defendia o modelo pelo qual havia se doutorado.

Nos primeiros programas, o corpo docente era integrado por professores das mais diferentes áreas, sem entrosamento temático entre eles. As disciplinas estruturavam-se em torno dos interesses dos professores, em geral baseadas em suas próprias teses de doutorado. Os alunos, por sua vez, propunham um projeto para ser orientado sem considerar as relações entre os seus interesses e a tradição temática e metodológica do orientador. A relação entre orientador e orientando era distante, não cabendo maiores envolvimentos do orientador na preparação geral do trabalho. Em muitos casos, o orientador era um dos críticos mais algozes da pesquisa, por ocasião da defesa.

Ao longo da década de 1970, a pós-graduação começou a ser orientada dentro de nova racionalidade em termos de finalidades, metas, competências, responsabilidades e recursos. A CAPES, através do Decreto-Lei ${ }^{\circ}$ 74.299, de julho de 1974, passou a ter o status de órgão central de direção superior, dotado de autonomia administrativa e financeira, com suas atribuições estabelecidas de acordo com as diretrizes fixadas pelo Plano Nacional de Pós-Graduação. Neste período, a agência passou a contar com a colaboração da comunidade acadêmica para subsidiar, com pareceres, a concessão de auxílios e bolsas. Em 1978, foi instituída a sistemática de avaliação para atender à necessidade de um maior acompanhamento 
dos cursos, em franco crescimento, e uma maior racionalização na distribuição de bolsas e de recursos. A partir de 1982, a CAPES consolida-se como gestora da pós-graduação, afirmando-se através da elaboração do II Plano Nacional de Pós-Graduação, implementado em 1983. Estava, também, consolidado o processo de monitoramento com as avaliações sistemáticas, visando com isso a geração de indicadores de custo/eficiência. Há também a preocupação em auxiliar os programas a contarem com a infra-estrutura necessária.

A consolidação gradativa da pós-graduação foi introduzindo vários desafios aos programas e às universidades. Era necessário contar com professores titulados, plano de carreira para contratação de professores, bibliotecas adequadas, gabinetes de professores e laboratórios equipados. Nas universidades, a assimilação das novas exigências foi lenta. A própria inserção dos programas de pós-graduação gerava conflitos com a graduação, e também entre os poucos professores titulados e a maioria de professores não titulados. Era difícil para os professores e muito mais para os alunos da época compreender a concepção de uma universidade que, além da formação profissional, proporcionasse atividades em pesquisa. A assimilação da pós-graduação não foi fácil, principalmente diante das instâncias superiores das instituições, constituídas na sua maioria por professores não titulados e pouco familiarizados com as questões propriamente universitárias.

$\mathrm{Na}$ concepção que se estabelecia no início dos anos 1980, a pós-graduação stricto sensu organizava-se em torno de uma área de concentração, contanto com estrutura curricular capaz de atender às exigências da formação geral, metodológica e temática. A área de concentração deveria ser estruturada em linhas de pesquisas bem definidas e delimitadas, em torno das quais seriam desenvolvidos os projetos das dissertações e das teses. $\mathrm{O}$ orientador passou a ter uma atuação mais ativa e comprometida com os projetos dos orientandos, tornando-se co-autor das publicações decorrentes. Para as áreas de ciências sociais e humanas, a mudança trouxe sérias discussões sobre o conceito de autoria. Nestas ciências, grande parte das pesquisas sofre de influência ensaísta, havendo maior liberdade e individualidade na preparação dos textos.

Muitos programas tiveram dificuldades de se adaptar às novas características da pós-graduação. Foi difícil compor um grupo de professores em torno de uma área de concentração, reformular currículos, definir linhas de pesquisas, e rever o conceito de autoria dos produtos decorrentes dos trabalhos de conclusão. Acrescentem-se, ainda, as dificuldades de infra-estrutura: bibliotecas, laboratórios, gabinetes para professores, e regime de trabalho.

\section{Quanto às Condições}

Ao mesmo tempo em que a CAPES se consolidava como gestora da pós-graduação, o Departamento de Psicologia da UFRGS recebia professores recém titulados e interessados em desenvolver uma estrutura para a realização da pesquisa. O primeiro deles foi Cláudio Simon Hutz, com doutorado pela University of Iowa em 1981, com a tese The effect of belief in premises and conclusions on children's logical reasoning. $\mathrm{O}$ segundo foi William Barbosa Gomes, com doutorado na Southern Illinois University - Carbondale, com a tese, Experiential psychotherapy and semiotic phenomenology. Várias tentativas foram feitas para atrair doutores para o Departamento: no exterior, no Brasil, e na própria universidade. Foi assim que Angela Maria Brasil Biaggio (1940-2003) abriu mão da posição de professora do Programa de Pós-Graduação da Faculdade de Educação da UFRGS para integrar a comissão organizadora do novo Programa em Psicologia, sendo a terceira docente a aderir à nova proposta. Biaggio obteve o doutorado na University of Wisconsin em 1967, sob orientação de Robert E. Grinder, com a tese Relationship among behavioral, cognitive and affective aspects of children's conscience. A quarta integrante foi Léa da Cruz Fagundes, uma professora do Departamento de Psicologia, reconhecida por seu pioneirismo nas pesquisas em epistemologia genética e computação, que acabava de concluir o doutorado na Universidade de São Paulo, com a tese Psicogênese das condutas cognitivas da criança com o mundo do computador, sob a orientação de Zélia Ramozzi-Chiarottino. Fagundes foi membro ativo do grupo de pesquisa de Antonio Battro (Argentina) e coordenava o Laboratório de Estudos Cognitivos. Deste grupo também fez parte o professor Cícero Emídio Vaz, um dos pioneiros no ensino de psicologia no Rio Grande do Sul, reconhecido por suas pesquisas sobre o Teste Projetivo de Rorschach (Vaz, 1980). Cícero Vaz era também funcionário do estado e estava cedido à UFRGS. Além de Biaggio, outros dois professores convidados a se integrarem à proposta de pós-graduação do Departamento de Psicologia da UFRGS foram Isolda e Harmut Günther. Tentou-se sua transferência da Universidade Federal da Paraíba (UFPB) para a UFRGS, mas isso não se concretizou porque a Isolda era professora titular e a UFRGS não concordou em alocar uma vaga de titular para uma transferência. Os nomes desses reconhecidos professores, que depois vieram a se transferir para a Universidade de Brasília, constaram no projeto original do Curso de Mestrado. Várias tentativas foram feitas para trazer outros professores doutores de outras regiões, mas não fomos bem sucedidos. O Rio Grande do Sul (RS) fica longe do centro do país, o deslocamento para outras regiões não era uma tradição brasileira e poucos acreditavam que valeria a pena uma mudança de tais proporções para ingressar num programa que estava apenas iniciando, organizado por dois professores inexperientes.

Uma das primeiras iniciativas do grupo que estava organizando o Curso de Mestrado foi a realização de um evento para discutir e avaliar a situação da pós-graduação em Psicologia no Brasil e, principalmente, para dis- 
cutir nosso projeto de pós-graduação. Tínhamos clareza da nossa falta de experiência e de vivência na pós-graduação no Brasil e reconhecíamos a necessidade de aconselhamento especializado.

Convidamos pesquisadores reconhecidos em diferentes áreas e procedentes de universidades de diversas regiões do Brasil. O interesse era saber quais aspectos favoreciam ou desfavoreciam a produtividade e a eficiência de um curso de pós-graduação. Estiveram presentes no evento: (a) Carolina Bori, do Programa em Psicologia Experimental da Universidade de São Paulo, na época presidente da Sociedade Brasileira para o Progresso da Ciência; (b) Aroldo Rodrigues, do Programa de Psicologia Social da Universidade Gama Filho, na época presidente da Associação Nacional de Pesquisa e Pós-Graduação em Psicologia; (c) João Todorov, do Programa de Psicologia Experimental da Universidade de Brasília e na época vice-reitor da referida Universidade; (d) Hartmut e Isolda Günther, do Programa de Psicologia Social da Universidade Federal da Paraíba; (e) David Carraher, do Programa de Psicologia do Desenvolvimento da Universidade Federal de Pernambuco; (f)
Marilda Lipp, do Programa de Psicologia Clínica da Pontifícia Universidade Católica de Campinas; (g) Eunice Alencar, da área de Psicologia do Desenvolvimento do Programa de Pós-Graduação da Universidade de Brasília; e (h) Monique Augras, Programa de Psicologia Clínica da Pontifícia Universidade Católica do Rio de Janeiro e, na época, Chefe do Centro Brasileiro de Pesquisas Psicossociais da Fundação Getúlio Vargas - Rio de Janeiro. A lista foi sugerida por Angela Biaggio e o perfil dos professores convidados representava a diversidade de interesses e métodos de pesquisa. $\mathrm{O}$ evento contou com financiamento do CNPq. A carta convite, reproduzida a seguir (Figura 1), é uma análise da situação da pesquisa e da pós-graduação no Rio Grande do Sul, seis anos depois da importante e histórica Mesa Redonda da Sociedade de Psicologia do RS, na qual Inúbia Duarte Andrade anunciava a suspensão do Curso de Mestrado da PUCRS, principalmente por falta de professores e infra-estrutura acadêmica (ver Mesa Redonda, 1980).

O documento seguinte (Figura 2) traz a programação das Mesas Redondas realizadas na sexta-feira, 03 de outubro de 1986, com os nomes e temas dos pesquisadores.

Porto Alegre, 17 de julho de 1986

Senhor(a) Professor(a)

O Rio Grande do Sul foi um dos estados pioneiros no ensino de psicologia no Brasil. A psicologia como ciência vem se desenvolvendo nesta região, tendo atingido um nível que exige a criação de programas formais para a preparação de pesquisadores. Existem hoje, sete cursos de graduação no Estado, mas nenhum Mestrado. O treinamento disponível na área de psicologia visa principalmente a formação de profissionais em áreas aplicadas, sendo escassas as oportunidades para a formação de docentes do ensino superior e de pesquisadores.

Este quadro começa a se alterar com a perspectiva de criação de um Mestrado em Psicologia na Universidade Federal do Rio Grande do Sul. O programa de Mestrado, por sua vez, teria como propósito o treinamento de docentes universitários para o desempenho de suas atividades e a produção de pesquisa básica de alta qualidade.

Marcando o início deste Mestrado, acreditamos que seria de muita importância reunir, pela primeira vez neste Estado, um grupo de renomados pesquisadores em Psicologia. Este encontro permitirá uma apreciação crítica da proposta do nosso pós-graduação, além de incentivar o pluralismo de abordagens e posturas científicas, exemplificar a necessidade da pesquisa básica em Psicologia, e atrair jovens pesquisadores. Espera-se, também, discutir, como está no Brasil, a situação da pesquisa básica e aplicada, e a produção e distribuição de textos em Psicologia.

O I ENCONTRO DE PESQUISADORES EM PSICOLOGIA NO RIO GRANDE DO SUL será promovido pelo Departamento de Psicologia da Universidade Federal do Rio Grande do Sul, com o apoio do CNPq, e terá como participantes professores e estudantes dos diversos cursos de Psicologia do Estado.

Assim, temos o prazer de convidá-lo(a) para participar deste I ENCONTRO e contribuir nas seguintes Mesas Redondas assinaladas:

Figura 1. Carta convite para o I Encontro de Pesquisadores em Psicologia no RS

No segundo dia do evento os professores convidados apresentaram comunicações sobre suas últimas pesquisas. Na primeira sessão, Carraher e Augras apresentaram trabalhos sobre as relações entre cognição, afeto e cultura. Na segunda, foram apresentados os trabalhos: "Motivação, mediação cognitiva, atribucional e rendimento acadêmico" (A. Rodrigues); "Menor abandona$d o$ " (H. Gunther), "Criatividade" (E. Alencar) e "Cognição e informática" (L. Fagundes).
A audiência, que não passava de 50 pessoas, era composta por professores e estudantes dos cursos de Psicologia da UFRGS e da PUCRS. Entre os estudantes o clima era de surpresa ou quase estranhamento diante do discurso e das exigências de uma pesquisa baseada em evidências. A abrangência temática fez com que fosse examinado cada aspecto da pós-graduação, enriquecido pelas diferenças entre os programas representados. Das discussões, consolidaram-se as diretrizes para a criação 
Das 9:00 às 12:00 horas

Principais Centros de Pós-Graduação e Pesquisa Psicológica no Brasil: Abordagens Metodológicas e Produção Científica. Ângela Biaggio, UFRGS (Coordenação). Marilda Lipp, PUCCAMP; Monique Augras, PUCRJ

(Debatedores).

- Características de um mestrado em psicologia cognitiva. David Carraher UFPE

- Política de coordenação na pós-graduação. Hartmut Gunther, UFBP.

- O mestrado em psicologia na UnB: Pesquisa básica apesar das circunstâncias. João Todorov, UnB

- A reconstrução de um mestrado: A experiência da Universidade Gama Filho. Aroldo Rodrigues, UGF

- Avaliação dos cursos de pós-graduação em psicologia. Carolina Bori, USP.

Das 14:00 às 15:30 horas

Realidade Brasileira e Pesquisa Científica. Cláudio Hutz (Coordenador), João Claudio Todorov (Debatedor)

- A força motivadora subjacente à produção científica no Brasil. Marilda Lipp, PUCCAMP

- Integração pesquisa-ensino no pós-graduação: Desafios e procedimentos. Monique Augras, FGV/RJ, PUCRJ

- Pesquisa para conhecimento ou pesquisa para decisão? Isolda Gunther, UFPB

Das 17:00 às 18:30 horas

Produção de textos científicos em psicologia. William B. Gomes (Coordenador); Aroldo Rodrigues, Carolina Bori, David Carrher, Marilda Lipp, e Monique Augras (Debatedores).

- Por que se sabe tão pouco sobre textos científicos em psicologia no Brasil? William B. Gomes, UFRGS

- A produção de textos científicos em psicologia: Necessidades e desafios. Eunice Alecar, UnB.

Figura 2. Programa do I Encontro de Pesquisadores em Psicologia do Rio Grande do Sul

do Curso de Pós-Graduação em Psicologia da UFRGS (Hutz, 1986).

Os visitantes sugeriram critérios para recrutamento e seleção de alunos, por exemplo, a exigência inicial de proficiência em inglês; mostraram a importância da coerência curricular em torno de uma formação básica e metodológica; e recomendaram que as pesquisas realizadas e os trabalhos de conclusão fossem coerentes com as linhas de pesquisa. Esperava-se, ainda, que o curso envidasse esforços para contar com um pequeno grupo de alunos, mas dedicados em tempo integral. Por fim, enfatizaram que o novo Programa privilegiasse tanto a formação de pesquisadores quanto a formação de docentes. As recomendações hoje parecem óbvias, mas não eram práticas correntes nos programas da época. Por exemplo, na maioria dos programas existentes a proficiência em língua estrangeira era um requisito a ser atendido ao longo do curso; enquanto para o nosso programa a língua estrangeira seria o inglês e a proficiência era requisito para aprovação no concurso de admissão. Outro exemplo, em muitos programas, o aluno comparecia apenas um dia por semana para as aulas, enquanto no nosso programa seria exigido tempo integral e trabalho em conjunto com o orientador nas dependências da universidade. As discussões com os professores visitantes, especialmente com Carolina Bori, Aroldo Rodrigues e David Carraher nos convenceram da importância da organização e manutenção de um ambiente acadêmico ativo e participativo no qual professores, alunos e pesquisadores visitantes pudessem interagir sistematicamente, evitando o trabalho isolado. Não se trata simplesmente de criar uma estrutura onde os professores e alunos são obrigados a permanecer num prédio, mas sim, de criar condições de trabalho e estudo que levem professores e estudantes a desejarem freqüentar o prédio.

Em sua forma de organização, o evento foi um precursor dos encontros da Associação Nacional de Pesquisa e Pós-Graduação em Psicologia (ANPEPP), uma iniciativa de Analucia Schliemann, na época vice-presidente (1985-1988), sendo o primeiro deles na cidade de Caruaru (PE) em 1988. O segundo encontro da ANPPEP, no ano seguinte, já foi em Gramado (RS) organizado pelo novo Programa de Pós-Graduação em Psicologia da UFRGS. Neste segundo encontro foi criado o formato de grupos de trabalho (GTs) que atualmente é um elemento central do evento.

O planejamento do Curso de Mestrado contou ainda com a importante colaboração de outros professores. Algumas dessas colaborações merecem destaque especial. O primeiro vai para Terezinha Feres Carneiro, na época coordenadora do programa da PUCRJ. O encontro com Terezinha Carneiro ocorreu de modo inusitado. Em 1986, na Reunião Anual de Psicologia de Ribeirão Preto, uma viagem prolongada devido a embarque em ônibus errado, propiciou uma importante conversa entre Terezinha Carneiro, Hutz e Gomes. A conversa demorou mais de uma hora e culminou com o convite para Terezinha Carneiro visitar a UFRGS no ano seguinte e colaborar no planejamento do novo programa. Um marco desta visita foi a entrevista que Terezinha Carneiro concedeu a Gomes e Hutz (1987). O segundo destaque vai para dois professores visitantes do Programa de Pós-Graduação em 
Educação da UFRGS: Robert E. Grinder (Arizona State University, EUA) e Amedeo Giorgi (University of Pittsburgh, EUA) (Gomes, 1986). Eles nos entusiasmaram a adotar a prática norte-americana de valorizar sobremaneira a apresentação do projeto de trabalho de conclusão, entre nós conhecido como exame de qualificação. A experiência tem mostrado que é nesta ocasião que a banca se sente mais a vontade para um exame profundo, podendo contribuir para mudanças que efetivamente qualifiquem o projeto. Assim, desde a primeira qualificação mantém-se a mesma banca para a qualificação do projeto e a defesa do trabalho concluído. Esse reconhecimento indica ainda que a internacionalização é parte das ações fundadoras do Programa. Deste modo, relações e intercâmbios com instituições e uso de periódicos estrangeiros para publicação é uma realidade na história do Programa. O terceiro destaque vai para a Profa. Dra. Mara H. Hutz que nos trouxe a experiência do bem sucedido Programa de Pós-Graduação em Genética, o primeiro da UFRGS. O primeiro regimento do nosso Curso de Mestrado tomou como modelo o regimento da Pós-Graduação em Genética. Por fim um registro curio-

Tabela 1

Composição do Corpo Docente de 1987 a 2010

\begin{tabular}{|c|c|}
\hline Professor Doutor & Permanência \\
\hline Cláudio Simon Hutz (Iowa/EUA) ${ }^{1}$ & 1987 - atual \\
\hline William Barbosa Gomes (Illinois/EUA) ${ }^{1}$ & 1987 - atual \\
\hline Ângela Biaggio (Wisconsin/EUA) ${ }^{4}$ & $1987-2003$ \\
\hline Lea da Cruz Fagundes (USP/Brasil) $)^{3}$ & $1987-2005$ \\
\hline César Augusto Piccinini (London/Inglaterra) ${ }^{1}$ & $1987-$ atual \\
\hline Tânia Mara Sperb (London/Inglaterra) ${ }^{2}$ & 1989 - atual \\
\hline Rita Sobreira Lopes (London/Inglaterra) & 1993 - atual \\
\hline Silvia Helena Koller (PUCRS/Brasil) & 1994 - atual \\
\hline José Luiz Caon (Paris/França) ${ }^{3}$ & $1995-2003$ \\
\hline Maria Alice Pimenta Parente (USP/Brasil) ${ }^{1,2}$ & $1997-$ atual \\
\hline Cleonice Alves Bosa (Lond/Inglaterra) & 1998 - atual \\
\hline Denise Ruschel Bandeira (Psi/UFRGS/Brasil) ${ }^{1}$ & 2000 - atual \\
\hline Débora Dalbosco Dell'Aglio (Psi/UFRGS/Brasil) ${ }^{1}$ & 2002 - atual \\
\hline Lisiane Bizarro Araújo (London/Inglaterra) & $2002-$ atual \\
\hline Lia Beatriz de Lucca Freitas (USP/Brasil) & 2005 - atual \\
\hline Clarissa Marceli Trentini (C.Médicas/UFRGS/Brasil) & 2005 - atual \\
\hline Jerusa Fumagalli de Salles (Psi/UFRGS/Brasil) & 2006 - atual \\
\hline Marco Antonio Pereira Teixeira (UFRGS/Brasil) & 2006 - atual \\
\hline Jorge Castellá Sarriera (UAM/Espanha) & $2007-$ atual \\
\hline Adriana Wagner (UAM/Espanha) & 2008 - atual \\
\hline Rosa Maria Almeida (Fisiologia/UFRGS/Brasil) & 2010 - atual \\
\hline
\end{tabular}

Nota. ${ }^{1}$ Professores que foram coordenadores do Programa; ${ }^{2}$ Professores aposentados que continuam credenciados como orientadores permanentes; ${ }^{3}$ Professores aposentados $;{ }^{4}$ Professor aposentando, orientador permanente, falecido em 2003.

O conceito de linha de pesquisa por sua logística e eficácia foi de extraordinária importância para o desenvolvimento e consolidação da pós-graduação stricto sensu so. As despesas na preparação da documentação para submissão do projeto à Pró-Reitoria de Pós-Graduação e à CAPES foram totalmente custeadas por Hutz e Gomes, pois não havia na época outra fonte de recursos. $\mathrm{O}$ principal custo foi de datilografia. A única máquina de escrever do Departamento de Psicologia fora furtada e foi necessário mandar datilografar o projeto.

O título das teses dos professores convidados para compor o Corpo Docente do novo Programa já sugeria a área de concentração em Psicologia do Desenvolvimento, embora esses trabalhos jamais viessem a se constituir disciplinas nos Cursos. O programa partia de uma convergência temática, mas em contexto de pluralidade teórica e metodológica. A esse grupo pioneiro juntou-se em seguida outro doutor em psicologia do desenvolvimento: César Augusto Piccinini, que acabava de voltar da University of London com a tese Children's atribution to academic and social events, defendida em 1987. Estava constituído o primeiro corpo docente e que dá início efetivo ao Programa, recebendo a primeira turma de 10 alunos em 1988, com bolsa de estudos à disposição de todos. A Tabela 1 traz a lista de todos os professores que lecionam ou lecionaram no Programa. 
a pesquisa é esforço concentrado, contínuo e colaborativo, (b) que o currículo é um estrutura voltada à investigação científica, e (c) que o ensino caracteriza-se pela formação e pela inovação, com vista ao incremento do pensamento crítico e da autonomia. Na proposta do Curso de Mestrado em 1987 havia uma única Linha de Pesquisa, Desenvolvimento Social e Cognitivo, definida como "investigação de determinantes e correlatos sociais e cognitivos do desenvolvimento psicológico, em suas várias manifestações, através de diferentes abordagens metodológicas". Destaque-se nesta definição a incrível afirmação de liberdade conceitual e metodológica. O programa mostrava-se livre de aprisionamentos doutrinários e de preconceitos contra métodos sejam eles de inspiração positivista, pós-positivista, quantitativos ou qualitativos. O Programa oferecia um ambiente livre para o pensamento, para criatividade, para a curiosidade científica e para a inovação. A ênfase era para a seriedade e o compromisso com o rigor metodológico e desenvolvimento científico.

Essa tem sido uma característica marcante do nosso Programa desde o seu início e, sem dúvida, é um dos elementos responsáveis pelo nosso sucesso. A liberdade epistemológica, metodológica, ideológica, enfim a liberdade de cada professor criar, pensar, produzir e pesquisar sobre a temática que desejar, com a metodologia que lhe parecer mais apropriada é absoluta. A única exigência é a manutenção da excelência que deve ser demonstrada através das publicações e outras formas de reconhecimento qualificado dos pares.

Seis anos após o início do Mestrado era inaugurado o Curso de Doutorado. O Corpo Docente já contava com 12 professores permanentes e dois colaboradores. No Projeto submetido em 1995, a Linha de Pesquisa original havia se desdobrado em oito: (a) Desenvolvimento sócio-moral; (b) Interação social e desenvolvimento; (c) Desenvolvimento da Sexualidade; (d) Desenvolvimento cognitivo e informática; (e) Estudos epistemológicos e fenomenológicos em desenvolvimento psicológico; (f) Pesquisa psicanalítica e suas aplicações à psicologia do desenvolvimento; (g) Construção, normatização e validação de instrumentos de avaliação psicológica, (h) Educação à distância - Rede informática para alfabetização em língua, ciência e tecnologia. $\mathrm{O}$ desdobramento expôs sérios mal entendidos entre o conceito de linhas e projetos de pesquisa. Não bastasse, em 1997 o relatório anual listava 19 linhas de pesquisa.

Em 1998, por recomendação do Comitê de Avaliação da CAPES as linhas de pesquisa são redefinidas e reduzidas a três: (a) Desenvolvimento Social e Aplicações; (b) Interação social, Desenvolvimento e Psicopatologia e (c) Processos Cognitivos Básicos e Aplicações. A boa e oportuna intervenção do Comitê permitiu a readequação dos projetos e a elucidação de mal entendidos entre definição de linhas e projetos de pesquisa. Linhas mais distanciadas dos objetivos centrais transferiram-se para outros Programas, como aconteceu com a Linha oito de 1995 que se transformou em um dos grandes eixos de um curso de doutorado interdisciplinar em Educação e Informática, iniciado também em 1995. A nova configuração sustentou cada linha de pesquisa em seu próprio mérito, sem vínculos maiores com professores ou laboratórios, dando a cada docente a liberdade de transitar entre elas. Em 2004 as linhas de pesquisa passam a ser quatro com o acréscimo de Medidas em Psicologia e suas Aplicações, de certa forma uma reconciliação do Programa com seus primórdios, pois as investigações psicométricas sempre estiverem presentes em muitos trabalhos de conclusão e publicações.

\section{Quanto aos Fundamentos}

O privilégio de contar com um grupo de consultores diferenciados e de tomar como modelo cursos de mestrado e doutorado de reconhecida excelência, levou a comissão organizadora a definir fundamentos que embasaram a preparação do projeto inicial, e que sustentaram as atividades do Programa durante todos esses anos. Esses fundamentos orientam o credenciamento de professores, a seleção de estudantes, as atividades didáticas, a preparação dos trabalhos de conclusão, as atividades de extensão e as políticas de gestão.

\section{Perfil do corpo docente}

Desde o início do Curso de Mestrado o credenciamento de professores exigia dedicação integral ao Programa, incluindo, naturalmente, atividades na Pós-Graduação e na Graduação. Esses professores deveriam apresentar forte compromisso com a pesquisa e com a produtividade sistemática. A convergência temática era importante, mas não impedia a abertura de novas frentes, com vistas à vitalidade e à renovação continuada do Programa. As linhas de pesquisa, embora apresentassem maior identificação com um ou outro laboratório, eram abertas a todos os professores, o que vem nos proporcionando aprofundamentos e aprimoramentos teóricos e técnicos, versatilidade e criatividade. A convergência temática inicial estimulava a diversidade teórica e metodológica, mas exigia compromisso com a pesquisa empírica e com conhecimento apoiado em evidência.

Com a transformação do Departamento em Instituto de Psicologia em 1996, foram criados três departamentos, atualmente denominados: (a) Psicologia do Desenvolvimento e da Personalidade, (b) Psicologia Social e Intitucional, (c) Psicanálise e Psicopatologia. Devido ao grande envolvimento dos professores do Programa com o primeiro departamento mencionado, eles vieram a ter forte influência no perfil dos professores admitidos nos anos seguintes. A expectativa atual é que um professor aprovado em concurso para o Departamento apresente perfil o mais próximo possível de Pesquisador Produtividade Nível 2 do CNPq. Tais cuidados favorecem a aprovação de professores pesquisadores seniores com experiência consolidada e de recém-doutores altamente promissores. A diversidade manifesta-se nas exaustivas discussões e deliberações sobre as ações pedagógicas e 
administrativas do Programa e nos seminários de pesquisa. Ressalte-se, todavia, a elevada coesão do corpo docente quanto ao compromisso com a produtividade colaborativa e com a ética.

\section{Perfil do corpo discente}

O recrutamento e a seleção de alunos são intensamente debatidos cada ano, seja quanto aos tópicos recomendados para inclusão no edital, seja quanto à preparação das provas. A expectativa é a aprovação de estudantes com vocação para a vida acadêmica e flexibilidade para a vida profissional de alto nível, se esse for o encaminhamento de carreira preferido. Entre os requisitos para aprovação, destaca-se a proficiência em inglês aplicada à leitura e a interpretação de textos científicos em Psicologia. Em outras palavras, não basta o conhecimento da língua inglesa para se sair bem na prova. $\mathrm{O}$ candidato deve ter familiaridade com questões metodológicas e com a tradição psicológica de artigos científicos. O sucesso nesta prova está fortemente associado ao bom desempenho no Curso.

No início do Programa e por alguns anos exigiu-se dos alunos dedicação integral, quando havia grande disponibilidade de bolsas. Com o aumento de matrícula as bolsas já não chegavam para todos e a dedicação integral foi flexibilizada. No entanto, o Programa mantém a posição de exigir dos alunos períodos de permanência nos Laboratórios, por entender que os grandes ensinamentos do Mestrado e principalmente do Doutorado estão na convivência continuada entre orientadores e orientandos e não em sala de aulas. As aulas são importantes para o domínio de determinadas habilidades e competências, mas o amadurecimento crítico e a autonomia para a investigação científica estão associados à relação privilegiada entre orientador e orientando.

\section{Atividades didáticas}

A proposta do Programa foi econômica e precisa no desenvolvimento da estrutura curricular. A ênfase foi o incremento de competências e habilidades em conceituação e crítica teórica (não na adesão a teorias) e em metodologia científica, com ênfase em métodos quantitativos e qualitativos. As atividades didáticas se caracterizaram como estudos avançados que culminavam na preparação de textos de revisão, materiais instrucionais para a graduação ou para outras finalidades, e projetos de pesquisa. Neste sentido, o melhor exemplo é o Seminário Avançado de Estudos Interdisciplinares, o tradicional encontro das segundas-feiras pela manhã, no qual professores, doutorandos e professores visitantes apresentam projetos e resultados de pesquisa. Todos os alunos de mestrado e dos dois primeiros anos do doutorado são obrigados a se matricularem neste Seminário. Professores e visitantes também frequentam o seminário, participando ativamente dos debates. Em cada semestre ocorrem entre 15 a 20 desses seminários, cabendo a cada mestrando preparar, por escrito, uma resenha crítica, em torno de mil palavras, para 12 desses seminários. As resenhas são avaliadas e discutidas com os estudantes de doutorado e servem a várias finalidades: (a) para os mestrandos é uma rica oportunidade para desenvolvimento de redação científica e crítica metodológica; (b) para o doutorando propicia o desenvolvimento de habilidades de supervisão. Como os pares mestrando/doutorando variam nos quatro semestres do Curso de Mestrado é também uma exposição à diversidade de ideias, à situação de supervisão e a estilos de redação científica.

Um dos objetivos da pós-graduação stricto sensu é a formação de docentes universitários. Alguns Programas chegaram a incluir em seus currículos alguma disciplina sobre metodologias e técnicas de ensino. A opção do PPG em Psicologia da UFRGS foi em outra direção. Apostou na força tutorial dos orientadores e na prática pedagógica dos orientandos. Desde o início do Programa, em 1987, os orientandos colaboram com orientadores na preparação de disciplinas para graduação, ministrando aulas, propondo trabalhos e práticas, e mesmo oferecendo disciplinas optativas. Essas atividades foram fortalecidas com curso de doutorado e hoje se constituem em um dos pontos altos do Programa. Posteriormente, a própria CAPES veio a reconhecer a importância dessas atividades e a exigi-las de seus bolsistas nos vários programas. A participação de estudantes de pós-graduação em atividades didáticas junto a seus orientadores é atualmente reconhecida como um importante fundamento na formação de mestres e doutores. Há inclusive um periódico dedicado ao tema, The Journal of Graduate Teaching Assistant Development, publicado pelo Institute of Teaching and Learning - University of Connecticut, EUA.

A interação entre pós-graduação e graduação ocorre nos laboratórios onde professores e estudantes de ambos os níveis desenvolvem pesquisas em conjunto, nas supervisões de projeto de pesquisa, e nas próprias disciplinas de graduação que contam com ativa participação dos mestrandos e doutorandos. Daí decorre a vasta produção científica que vem distinguido entre seus pares desde a sua fundação.

\section{Trabalhos de conclusão}

O Programa sempre foi sensível aos prazos de conclusão no mestrado e no doutorado, mas atento as peculiaridades das pesquisas que estavam sendo realizadas e as características do orientando. Com isto evitou-se prolongamentos injustificados, mas não cerceou o tempo necessário à preparação de trabalhos efetivamente diferenciados, ou aos casos delicados que demandavam maior atenção e acompanhamento. O Programa foi um dos primeiros a adotar as Normas de Publicação da American Psychological Association, e a incentivar a preparação dos trabalhos em forma de artigos e em língua inglesa. A ênfase é para a pesquisa empírica tanto nas dissertações quanto nas teses, não excluindo capítulos teóricos se apropriados. 


\section{Atividades de extensão}

O Curso de Doutorado desde o seu início exigiu que os doutorandos desenvolvessem projetos de extensão baseados nas pesquisas das teses. A ideia foi incentivar o desenvolvimento de aplicações baseadas nas pesquisas. As ações decorrentes têm se caracterizado por cursos de atualização ou por intervenções em serviços ou escolas. Essa atividade serve também para dar retorno dos resultados da pesquisa aos indivíduos ou comunidades que participaram da coleta de dados. A iniciativa é hoje reconhecida como uma das principais realizações da extensão no Instituto de Psicologia.

\section{Políticas de gestão}

A administração e articulação dos vários segmentos do Programa não seriam possíveis sem uma política de gestão eficiente. O Estatuto e Regimento da Universidade determinam que o Programa tenha um regimento próprio, um coordenador, um coordenador substituto, uma comissão coordenadora e um conselho de professores. Evidentemente, nosso programa tem tudo isso. A coordenação e a comissão coordenadora são eleitos pelos professores. Não há imposições externas. Há também uma representação de alunos na comissão coordenadora e no conselho de professores. Até hoje, tivemos seis coordenadores no Programa e, quando este artigo for publicado, estaremos elegendo o sétimo coordenador. O mandato é de dois anos, podendo haver uma reeleição. Nunca tivemos uma eleição disputada por dois candidatos e, é bem verdade que atualmente, graças ao crescimento da pós-gradução brasileira e a complexidade do relatório anual da Capes tornou-se quase impossível encontrar algum professor que queira se candidatar ao cargo.

Em contrapartida, o número elevado de professores que já passou pela experiência da coordenação facilita muito a administração do Programa, pois há uma sensibilidade maior para as necessidades burocráticas, documentação, prazos, normas e regras. Embora vivamos há anos com excesso de atividades, o Programa promove reuniões quinzenais, em média duas horas de trabalho, que deveriam ser da comissão coordenadora. Porém, praticamente todos os professores (inclusive aposentados) comparecem às reuniões com direito a voz e voto. Há anos as reuniões tornaram-se reuniões do conselho de professores e, embora isso aparentemente pareça um grande desperdício de tempo e recursos, a participação ativa de todos os professores no processo decisório e na vida cotidiana do Programa tem gerado uma dinâmica muito diferenciada com relação à maioria dos programas de Pós-Graduação. Não apenas por desenvolver uma forma mais democrática de administrar o programa, compartilhar recursos e dividir tarefas, mas também pelo compartilhamento de informações e pela transparência de todas as ações. Além disso, mantemos uma reunião permanente por e-group, o que evita a necessidade de reuniões semanais.

\section{Considerações Finais}

O cuidado e o cultivo da memória institucional e a revisão das anotações que vão compondo a história constituem não apenas o reconhecimento, mas compromisso permanente com a qualidade e com o futuro do Programa. O PPG em Psicologia da UFRGS é uma decorrência da tradição cultural e intelectual do Rio Grande do Sul, com perfil acadêmico induzido por consultoria de altíssimo nível, representando o que melhor havia na área da psicologia nos meados de 1980. O modo de formular objetivos de curso, definir linhas de pesquisa, estruturar currículo, formular critérios para ingresso de alunos, determinar a relação dos professores com o Programa representava importante passo na concretização das novas metas e concepções da pós-graduação esperadas pela CAPES. Neste sentido, o Programa se beneficiou do espírito do tempo e do lugar. Era um Programa que acontecia em um bom momento de gestão universitária na UFRGS, idealizado por jovens professores, assessorado por especialistas efetivamente envolvidos com a pesquisa e a pós-graduação.

Anotações históricas também trazem dificuldades e percalços que uma instituição, programa ou projeto enfrentam ao longo do tempo. Sensível às boas iniciativas da CAPES, o Programa ofereceu três cursos de mestrado interinstitucional com reais benefícios aos docentes de universidades promissoras do Rio Grande do Sul, mas que prejudicaram as metas gerais de produtividade e o tempo de titulação, prontamente assinaladas pela CAPES No entanto, a abertura ao debate e à crítica interna permitiu que tais dificuldades fossem revistas e reavaliadas quando do envolvimento em outros projetos congêneres.

O Programa pôde contar, no decorrer da sua história, com estabilidade do Corpo Docente. A maioria dos professores fundadores continua ativa colaborando tanto no ensino quanto na pesquisa, servindo de apoio, inspiração e incentivo aos professores que vieram depois. $\mathrm{O}$ Programa teve a felicidade de receber tanto professores experientes e reconhecidos em seus respectivos campos de atuação, como jovens professores com clareza das exigências da pesquisa competitiva e dispostos a enfrentar as exigências e os desafios da pós-graduação.

$\mathrm{O}$ grande sucesso alcançado pelo Programa e incrementos no corpo docente e na internacionalização repercutiu no aumento do corpo discente e na publicação qualificada. No entanto, representa sérios desafios à unidade, à qualidade da formação, e às condições de infraestrutura. Todavia, trata-se de um bom problema e sérios esforços estão sendo envidados para ampliar as instalações atuais.

$\mathrm{O}$ conjunto de condições fundadoras e de fundamentos norteadores anotadas neste artigo constitui um bom efeito de origem, poderoso na determinação, na vontade de realização e no empenho de manter o nível de excelência conquista em mais de duas décadas. 


\section{Referências}

Ferreira, M., \& Moreira, R. (2002). Capes, 50 anos. Brasília, DF: Coordenação de Aperfeiçoamento de Pessoal de Nível Superior.

Gauer, G., \& Gomes, W. B. (2002). O curso da reforma: Ensino de Psicologia na Universidade Federal do Rio Grande do Sul (1971-1979). Psicologia: Reflexão e Crítica, 15(3), $497-$ 514.

Gomes, W. (1986). Uma conversa com Amedeo Giorgi. Psicologia: Reflexão e Crítica 1(1), 85-90.

Gomes, W. B., DaSilviera, A., \& Gauer, G. (2006). Pesquisa e Pós Graduação. In W. B. Gomes (Ed.), Psicologia no Estado do Rio Grande do Sul (Cap. 10). Porto Alegre, RS: Museu Virtual da Psicologia. Retrieved June 23, 2010, from http://www6.ufrgs.br/museupsi/PSI-RS/sumars.htm

Gomes, W. B., \& Hutz, C. (1987). A prática clínica e o trabalho acadêmico na Universidade: Uma entrevista com a psicóloga clínica Terezinha Feres Carneiro. Psicologia: Reflexão e Crítica, 2(1/2), 73-78.

Hutz, C. (1986). O I ${ }^{\circ}$ Encontro de Pesquisadores em Psicologia no Rio Grande do Sul. Psicologia: Reflexão e Crítica, 1(1), 91-97.

Lhullier, C., \& Massimi, M. (2006). Psicologia nas teses da Faculdade de Medicina de Porto Alegre. In W. B. Gomes (Ed.), Psicologia no Estado do Rio Grande do Sul (pp. 2555). Porto Alegre, RS: Museu Virtual da Psicologia.

Lourenço Filho, M. B. (1955). Psicologia no Brasil. In F. Azevedo (Ed.), As ciências no Brasil (Vol II, pp. 263-296). São Paulo, SP: Melhoramentos. (Reimpresso pelos Arquivos Brasileiros de Psicologia Aplicada, 23(3), 113-142, 1971)

Lourenço Filho, M. B. (1971). A psicologia no Brasil nos últimos 25 anos. Arquivos Brasileiros de Psicologia Aplicada, 23(3), 143-151. (Original work published 1969)

Mesa Redonda (1980). Revista da SPRGS, 8, 3-12.

Vaz, C. E. (1980). O Rorschach: Teoria e desempenho. Porto Alegre, RS: Artes Médicas.

Vaz, C. E. (1987). Editorial. Psico, 14(2), 5-6. 